\title{
Back to Medieval Witch Burning
}

\author{
Stephan Rössner \\ Obesity Unit M 73, Karolinska University Hospital Huddinge, Stockholm, Sweden
}

These are hard times for Swedish experts in nutrition, dieticians, and clinicians working with obesity and diabetes and with the Swedish National Food Administration. This establishment, which for long time has based its treatment strategies on international recommendations, adapted for Swedish conditions, is presently under severe crossfire, and its competence questioned. In spite of all immigration $(10 \%$ of our 9 million inhabitants by now), Sweden is a small homogenous country enjoying the benefits of a reasonably wealthy society. Although the prevalent data for obesity and diabetes are increasing in parallel to the changes seen elsewhere in the world, Sweden is still in the lower European tertile for obesity prevalence.

The Swedish standard dietary recommendations have been filtered through processes using the best international information available, which has been digested by Swedish experts with an international and national reputation. They are not different from those in many other countries of similar structure [1].

All this has now been questioned. In Sweden the benefits of high-fat diet have been successfully promoted, mainly through the activities of one general practitioner who without any academic qualifications whatsoever has caused severe turmoil [2]. As the situation is with many fraud diets, her recommendation is based on her personal experience, when she lost weight on a high-fat diet and now promotes high fat to the entire Swedish population in extremely aggressive terms. The scientific rationale which is referred to is one article by Vesti Nielsen [3], published in a journal, which barely has any impact whatsoever in scientific index systems. The advantage claimed is that high-fat diets do not cause insulin release and hence reduce the risk for development of diabetes. The longterm effects of a high-fat diet on atherosclerosis are never discussed or seen as a problem.

This could be seen as another weird program launched by an enthusiast along the well-known lines that such diet generally run: Scientific break-through through personal insight, own benefit, dramatic results promised etc. However, in this case a reason why this now has reached a national level, where the high-fat diet is discussed almost daily, is the embracement of these ideas by the media. Classically, journalists love the David-versus-Goliath story - the little man fighting against the system, trying to get through bureaucracy, incompetent rigid administrators etc. The message has thus been widely publicized, the diet recommendations appear in evening newspapers and have been published in a book. The author herself admits that she can barely read English but that she 'picks up the sound ideas from the grassroots'. She now argues (autumn 2009) that her diet protects against the swine flu and that people adhering to her diet do not develop cancer.

When this program is attacked on scientific background, the experts are immediately dismissed because they are all seen as corrupt and bought by the food industry [4]. Sweden is a small country, and the few nutritional experts available have often been used as experts and consultants for the food industry, but nobody disputes that they have declared their conflicts of interest, which for instance are published on the web page of the Swedish National Food Administration (Livsmedelsverket), where many of these experts have been working as unpaid consultants over many years.

The Administration in itself is now questioned, the need for dietary advice to the general Swedish public is disputed, and senior professors have literarily been chased by the media with a wording that is extremely harsh, such as a pediatrician being accused of 'murdering Swedish children' unless more fat is not allowed in the school canteen food. (Sweden like Finland has had free school lunches for more than 50 years, and the nutritional balance of those meals has of course always been well calculated, although the amount of money allocated for these meals and hence the quality may vary from region to region.) Now the canteen staff is hunted by parents who hand over butter to the staff, demanding that this extra fat be included into the school meals of their kids.

The half-life of these prophets has generally been short and their influence over time minimal. What is interesting and distressing in this case is the penetration of a message without any scientific backing and the enthusiastic support received by

\section{KARGER}

Fax +497614520714

Information@Karger.de

www.karger.com (c) 2009 S. Karger GmbH, Freiburg

Accessible online at:

www.karger.com/ofa
Prof. Dr. Stephan Rössner

Obesity Unit M 73, Karolinska University Hospital Huddinge

14186 Stockholm, Sweden

Tel. +46 858582483

Stephan.Rossner@ki.se 
the media. At present even some octogenarians who once enjoyed considerable respect as brilliant Swedish scientists and clinicians have joined the bandwagon, probably in the aspiration to once more be seen in the media and lending support for the old joke, when evidence-based medicine becomes eminence-based instead.

Nobody knows the end of the story. This is also a media favorite, 'the never-ending story', compare for instance the classical O.J. Simpson affair with continuous new unexpected events. Obviously the general public is rightly confused. Scientists have always argued that, in spite of minor discrepancy which is part of the nature of scientific development, the general dietary advice are similar and have not changed much over time. They are also fairly consistent in different parts of the world, with similar lifestyle patterns and food supply. As matters have developed now, the media has forced Swedish top experts to leave their posts because of alleged corruption; experts have been ridiculed, and the female physician who once started the whole movement is still enjoying popularity.

One may discuss whether dietary advice to a general public on a national basis is overshoot. Sweden is an extremely well-regulated country, and it could be argued that there is no need for Big Brother watching what Swedes choose to eat. However, in a European perspective Sweden is probably not much different from many other European countries: CCTV (closed circuit television) watches its inhabitants who are registered many times per day in countries like the UK, where also bizarre registration of parents driving kids on the block to sports events was recently introduced to identify potential pedophilics. The size of fruits and the shape of cucumbers have been regulated by the European Union etc.

The Swedish National Food Administration responded to the criticism by putting together on their homepage a number of studies demonstrating the association between high-fat diet and health risks [5]. The list ended with 74 studies showing an increased risk, eight not demonstrating any risk, but none showing any actual benefit of the high-fat diet. However, the Administration may have regretted this move, when it was ferociously attacked by the high-fat proponents for being extremely selective.

This may well be seen as a Swedish affair, but has reached international interest. In a recent comment in the Lancet, Mann and Nye [6] from New Zeeland are baffled why of all places this should happen in Sweden. And, if it happens there, who knows when it happens somewhere else.

\section{References}

1 WHO: Diet, nutrition and the prevention of chronic diseases: report of a Joint WHO/FAO Expert Consultation. 2003. www.who.int/dietphysicalactivity/ publications/trs916/download/en/index.html.

2 Dr Dahlqvist's Blog: Introduction to LCHF: my diet programme for LCHF given an explanation of what it is about. Jan 15, 2008. http://blogg.passagen.se/ dahlqvistannika.
-3 Vesti Nielsen J, Jönsson E, Nilsson A-K: Lasting improvement of hyperglycaemia and bodyweight: low-carbohydrate diet in type 2 diabetes - a brief report. Upsala J Med Sci 2005;110:69-74.

4 Holm LE: Social experts in nutrition issues. March 18, 2008. www.socialstyrelsen.se/Aktuellt/Nyheter/ 2008/Q1/akt080318.htm (accessed April 24, 2009) (in Swedish).
5 Livsmedelsverket (National Food Administration): Studies on saturated fat - two lists. www.slv.se/ templates $/ S L V \_$Page.aspx?id $=22414$ and eps.

6 Mann J, Nye ER: Fat diets in Sweden, of all places. Lancet 2009;374:767-9. 